\title{
ChemComm
}

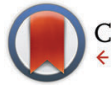

CrossMark \&lick for updates

Cite this: Chem. Commun., 2016, 52,6111

Received 8th March 2016, Accepted 5th April 2016

DOI: $10.1039 / c 6 c c 02078 j$

www.rsc.org/chemcomm

\section{Luminescence of a binuclear europium complex bearing a 4-nitrophenolate chromophore: a different way of seeing $\mathrm{pH}$ dependence $\dagger$}

\author{
Octavia A. Blackburn, ${ }^{a}$ Manuel Tropiano, ${ }^{a}$ Louise S. Natrajan, ${ }^{b}$ Alan M. Kenwright ${ }^{c}$ \\ and Stephen Faulkner*a
}

\begin{abstract}
A europium complex derived from NP-(DO3A $)_{2}$ exhibits $\mathrm{pH}$-dependent europium-centred luminescence following excitation of the nitrophenolate chromophore. Such behaviour is not observed with an analogous mononuclear complex, suggesting coordination of both lanthanide ions to the phenolate oxygen in the emissive species.
\end{abstract}

Lanthanide luminescence has proved to be an invaluable tool in bioassays over more than three decades, not least because the long-lived luminescence associated with lanthanide-centred emission can readily be separated from background signals arising from scattered light and autofluorescence using timegating techniques. When sensitising chromophores are used to circumvent the inherently low probability of $\mathrm{f}-\mathrm{f}$ transitions in absorption, very low (sub-fM) detection limits can be achieved in assays. Such approaches have since been extended to luminescence imaging microscopy, and exploited in imaging changes in a wide variety of biological analytes. ${ }^{1}$

Sensitised luminescence generally occurs through the chromophore-centred triplet state, which consequently must be higher in energy than the lanthanide emissive state. This restricts the range of chromophores that can be used to sensitise lanthanide ions that emit in the visible region of the spectrum. Attempts to circumvent this problem have involved using multi-photon excitation to excite relatively simple antenna chromophores, ${ }^{2}$ changing the lanthanide ion so that near-IR emission is observed following visible light excitation, ${ }^{3}$ or using antenna chromophores with small singlet-triplet energy gaps to maximise the potential excitation wavelength. ${ }^{4}$ The first two approaches require specialised equipment, while the third has been restricted in scope by the relatively limited number of suitable chromophores.

\footnotetext{
${ }^{a}$ Chemistry Research Laboratory, University of Oxford, Mansfield Road, Oxford OX1 3TA, UK. E-mail: Stephen.Faulkner@keble.ox.ac.uk

${ }^{b}$ School of Chemistry, University of Manchester, Oxford Road, Manchester M13 9PL, UK

${ }^{c}$ Department of Chemistry, University of Durham, South Road, Durham DH1 3LE, $U K$

$\dagger$ Electronic supplementary information (ESI) available: Synthetic methods and procedures, additional photophysical spectra. See DOI: 10.1039/c6cc02078j
}

The pathways involved in sensitisation can be exploited to give rise to $\mathrm{pH}$ dependent changes in luminescence, for instance by changing the energy transfer mechanism ${ }^{5}$ or by introducing new electron transfer pathways for non-radiative quenching of the lanthanide emissive state. ${ }^{6}$ Alternatively, changes to the coordination sphere of the lanthanide ion can be induced by deprotonation of neighbouring carboxylate or sulfonamide groups so that they can act as chelating ${ }^{7}$ or bridging $^{8}$ ligands only in well-defined $\mathrm{pH}$ ranges.

For a number of years, we have been exploring the properties of kinetically stable binuclear and bimetallic lanthanide complexes, and using them to prepare more complicated molecular architectures that exploit their potential as building blocks in covalently linked and self-assembling architectures. Their stability can be remarkable, with complexes remaining intact even under the forcing conditions of diazotisation. ${ }^{9}$

We now report the synthesis and spectroscopic properties of $\mathrm{Eu}_{2} \cdot \mathbf{1}$, which contains two lanthanide-binding domains linked by a 2,6-dimethyl-4-nitrophenolate unit. This complex was found to exhibit remarkable luminescence properties, which we now report in detail. The analogous mononuclear complex, Eu.2, was also synthesised and studied for comparison.

The compounds $\mathrm{Eu}_{2} . \mathbf{1}$ and Eu.2 were prepared from the wellknown triester, $3,{ }^{10}$ as shown in Scheme 1. 2,6-Bis(bromomethyl)4-nitrophenol (4) was synthesised by a literature procedure ${ }^{11}$ and reacted with 3 to yield the tert-butyl protected ligand, NP-(DO3A $)_{2}$, 6; an analogous reaction provided NP-DO3A, 7. Removal of the tert-butyl groups in acidic media and subsequent complexation with europium(III) trifluoromethanesulfonate in water gave $\mathrm{Eu}_{2} .1$ and Eu.2.

To our surprise, we observed that $\mathrm{Eu}_{2} .1$ exhibits luminescence from the europium centres upon both UV excitation and upon excitation with visible light at $405 \mathrm{~nm}$. 4-Nitrophenolates have long been known to be useful and effective chromophores; for instance 4-nitrophenyl esters have been widely used to follow the progress of reactions that involve the formation of 4-nitrophenolate. ${ }^{12}$ However, they have very low fluorescence quantum yields as a consequence of efficient formation of the 

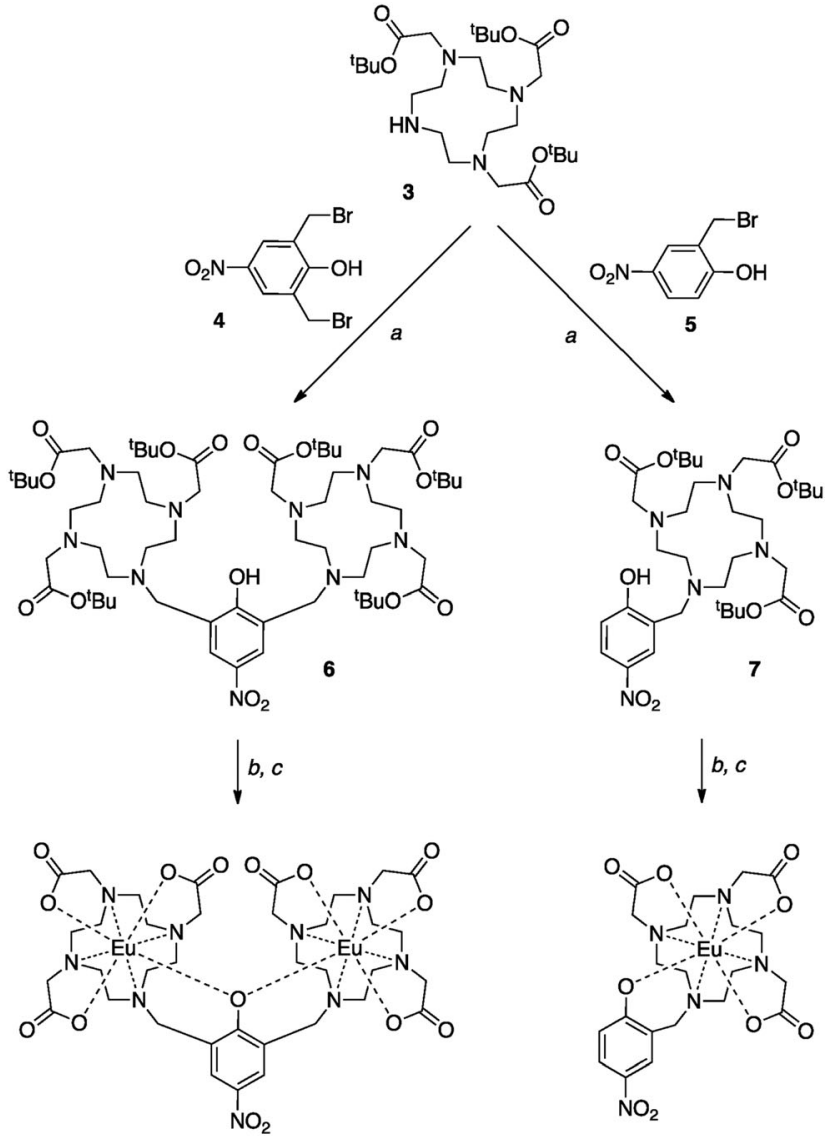

$\mathrm{Eu}_{2} \cdot 1$

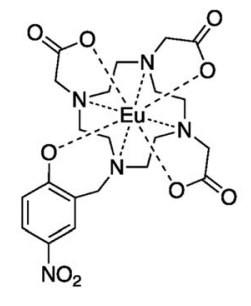

Eu.2

Scheme 1 Synthesis of $\mathrm{Eu}_{2} .1$ and Eu.2; (a) $\mathrm{MeCN}, \mathrm{Na}_{2} \mathrm{CO}_{3}$; (b) TFA, DCM; (c) $\mathrm{Eu}(\mathrm{OTf})_{3}, \mathrm{H}_{2} \mathrm{O}$.

triplet excited state from the $\mathrm{S}_{1}$ state. Nevertheless, 4-nitrophenolates have not (to our knowledge) previously been used to sensitise formation of lanthanide-centred excited states. With this in mind, we resolved to study the photophysical properties of the complexes $\mathrm{Eu}_{2} .1$ and $\mathrm{Eu} .2$ in more detail.

The absorption spectrum of $\mathrm{Eu}_{2} . \mathbf{1}$ varies dramatically with $\mathrm{pH}$, extending to longer wavelength as the $\mathrm{pH}$ is reduced, with $\lambda_{\text {max }}$ shifting from around $340 \mathrm{~nm}$ at high/neutral $\mathrm{pH}$ to around $380 \mathrm{~nm}$ at low pH (Fig. 1a), although it is clear that more than one transition contributes to this region of the spectra, especially at high $\mathrm{pH}$. This contrasts with the behaviour of 4-nitrophenol itself, in which $\lambda_{\max }$ shifts from around $400 \mathrm{~nm}$ at high $\mathrm{pH}$ to around $320 \mathrm{~nm}$ at low $\mathrm{pH}$ once the 4-nitrophenolate is completely protonated. In earlier studies on phenol bridged binuclear complexes, we have observed behaviour consistent with the co-existence of a number of isomers. Noting that an ytterbium complex closely related to $\mathrm{Eu}_{2} . \mathbf{1}$ exhibits behaviour consistent with the presence of two distinct lanthanide environments on the luminescence timescale (here microseconds), ${ }^{13}$ we can begin to draw some conclusions about the structural behaviour of the complex in solution.

At low $\mathrm{pH}$, it would be expected that the more open conformers (e.g. B, C in Scheme 2) where the nitrophenolate may be protonated would play a more significant role. The absorption spectra in Fig. 1 can be taken to suggest that $\mathrm{C}$ exists in
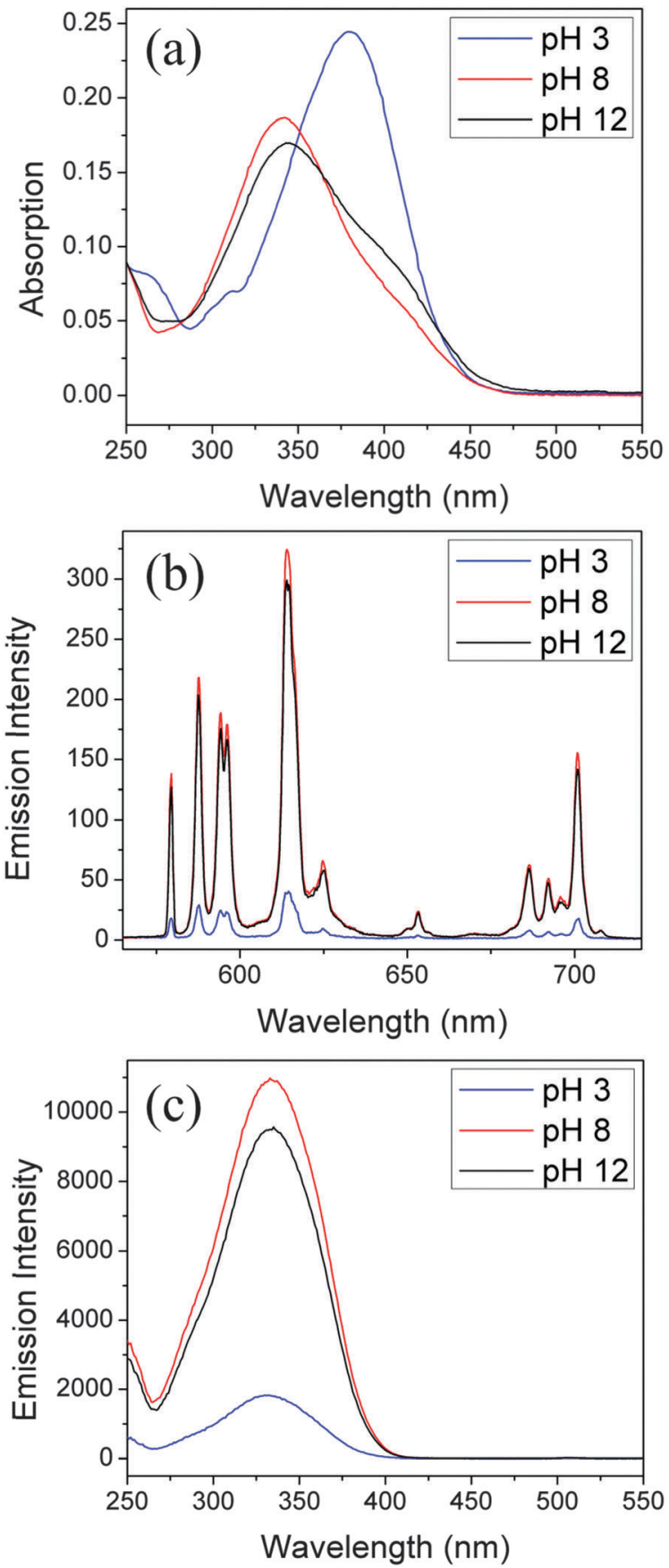

Fig. 1 Variations in the spectroscopic properties of $\mathrm{Eu}_{2} .1$ in $\mathrm{H}_{2} \mathrm{O}$ with $\mathrm{pH}$, all measured at the same concentration: (a) absorption spectra; (b) emission spectra $\left(\lambda_{\mathrm{ex}}=330 \mathrm{~nm}\right)$; (c) excitation spectra $\left(\lambda_{\mathrm{em}}=615 \mathrm{~nm}\right)$.

negligible quantities at higher $\mathrm{pH}$, and is the minor component of the mixture even at $\mathrm{pH}$ 3. More surprisingly, the major component at low $\mathrm{pH}$ is a phenolate species with absorption around $380 \mathrm{~nm}$. We can expect that coordination of two lanthanide ions to the phenolate oxygen will reduce the wavelength at which the absorption maximum is observed, suggesting that A dominates at high $\mathrm{pH}$, while $\mathrm{B}$ is the major isomer at $\mathrm{pH} 3$.

Excitation and emission spectra for complex $\mathrm{Eu}_{2} . \mathbf{1}$ are shown in Fig. 1, while key data is tabulated in Table 1. Excitation across 

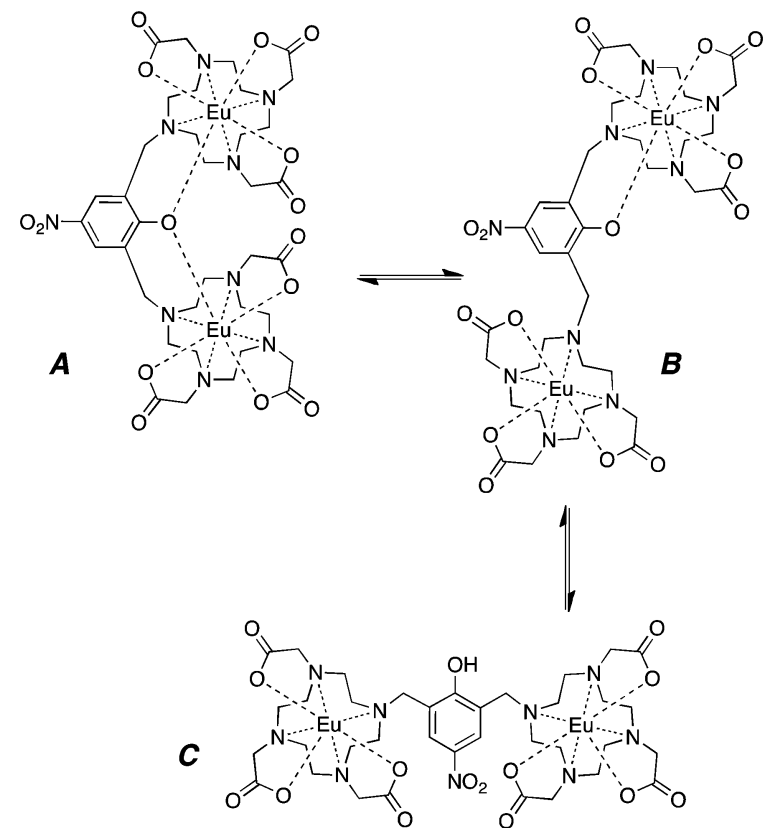

Scheme 2 Speciation in $\mathrm{Eu}_{2} .1$.

Table 1 Photophysical data for $\mathrm{Eu}_{2} .1$ in water as a function of $\mathrm{pH}$

\begin{tabular}{llllll}
\hline $\mathrm{pH}$ & $\lambda_{\max } / \mathrm{nm}$ & $\lambda_{\text {exc }} / \mathrm{nm}$ & $\tau_{\mathrm{D}_{2} \mathrm{O}} / \mathrm{ms}$ & $\tau_{\mathrm{H}_{2} \mathrm{O}} / \mathrm{ms}$ & $q$ \\
\hline 3 & 380 & 334 & 0.52 & 0.49 & 0 \\
8 & 342 & 334 & 0.82 & 0.61 & 0.2 \\
12 & 345 & 334 & 0.80 & 0.63 & 0.1
\end{tabular}

a broad range of wavelengths, extending into the visible region, resulted in observation of europium-centred emission. Furthermore, while the intensity of the emission varied with $\mathrm{pH}$, the form of the spectrum remains unchanged over a broad $\mathrm{pH}$ range (Fig. S1, ESI $\dagger$ ). The form of the observed excitation spectrum is also unchanged across the whole $\mathrm{pH}$ range studied, and closely resembles the absorption spectrum that we assigned to species A (Fig. S3, ESI †). These observations suggest the presence of a single emissive species, in which the two lanthanide ions are bridged by the phenolate oxygen atom. The luminescence lifetimes measured at different $\mathrm{pH}$ values give low $q$ values of $\leq 0.2$ (Table 1 ) and are within error of one another, consistent with a single emissive species. The relative lack of hydration at the metal centres of the emissive complex would be consistent with structure A where the conformational constraints imposed by phenol coordination force a closed structure where close approach of solvent is restricted.

To probe this further, we also studied Eu.2, a mononuclear analogue of $\mathrm{Eu}_{2} . \mathbf{1}$. The absorption spectrum of Eu.2 behaves similarly to 4-nitrophenol with changing $\mathrm{pH}$ (Fig. S6 and S7, ESI $\dagger$ ) with the appearance of a higher energy band on lowering the $\mathrm{pH}$, although the $\mathrm{p} K_{\mathrm{a}}$ of the phenol is clearly affected by the lanthanide containing substituent. In this complex, the uncoordinated phenolate appears to dominate even at low $\mathrm{pH}$. This complex showed no sensitised emission across a broad $\mathrm{pH}$ range, implying that coordination sensitised emission is not observed in cases where only one lanthanide is able to

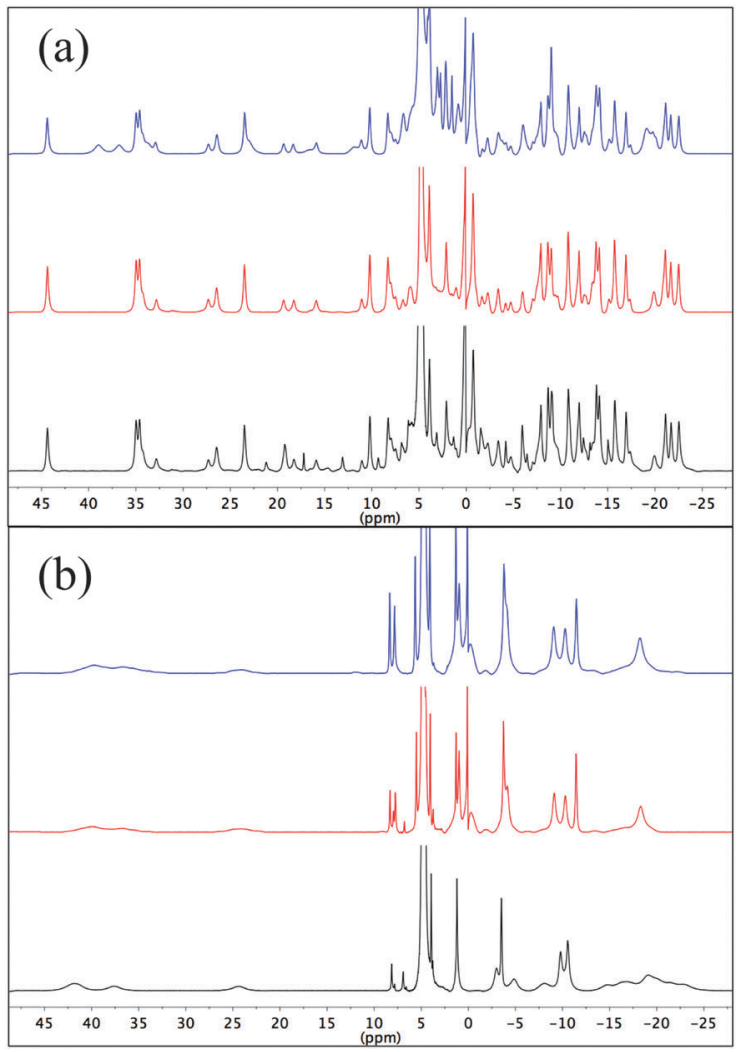

Fig. $2{ }^{1} \mathrm{H}$ NMR spectra of (a) Eu 2.1 and (b) Eu. 2 in $D_{2} \mathrm{O}(298 \mathrm{~K}, 400 \mathrm{MHz})$ at pH 3 (blue), 7 (red) and 12 (black).

coordinate to the phenolate. The lack of observed europiumcentred emission from Eu.2 concurs with a previous study of this complex by Sherry and co-workers who postulated that the emissive state was rapidly quenched by a ligand to metal charge transfer (LMCT) state. ${ }^{14}$ Triplet energy measurements on Gd.2 and $\mathrm{Gd}_{2} .1 \$$ (Fig. S4 and S8, ESI $\dagger$ ) revealed triplet energies of around $20500 \mathrm{~cm}^{-1}$ for $\mathrm{Gd}_{2} .1$, and $18100 \mathrm{~cm}^{-1}$ for Gd.2. However, the complex speciation observed in these systems means that these values need to be treated with caution, though it is clear that sensitised luminescence is thermodynamically feasible in both cases.

Our hypothesis as to the nature of the luminescent $\mathrm{Eu}_{2} . \mathbf{1}$ species was borne out by an NMR study. The ${ }^{1} \mathrm{H}$ NMR spectra of Eu.2 across a broad pH range (Fig. 2b) are characterised by broad peaks which change position at high $\mathrm{pH}$, which would be consistent with fast exchange between diastereomeric forms of a seven-coordinate complex on the timescale of the NMR experiment.

The ${ }^{1} \mathrm{H}$ NMR spectra of $\mathrm{Eu}_{2} .1$ at varying pH (Fig. 2a) offer an immediate contrast; the spectra are dominated by two sets of sharp resonances (possibly more) whose positions are $\mathrm{pH}$ independent. At low $\mathrm{pH}$, a minor isomer is also observed in which broader lines are seen at similar positions to those of Eu.2, consistent with a heptadentate species. A different set of minor peaks is observed at higher $\mathrm{pH}$; these are sharp, possibly corresponding to coordination of hydroxide at the lanthanide centres. It is clear that the major species in all cases is in slow (or zero) exchange with the visible minor isomer. 
Taken together, these results lend weight to the hypothesis that the emissive species in $\mathrm{Eu}_{2} .1$ is one in which both lanthanides are coordinated to the metal centre. It seems clear that the Lewis acidity of both centres is required if we are to modulate the chromophore excited state to the point where it becomes a useful sensitiser.

In conclusion, this work shows the importance of structure and isomerism in controlling lanthanide luminescence behaviour. We believe this to be a highly unusual system in that the photophysical properties of the binuclear complex differ dramatically from those of the mononuclear analogue. This study adds weight to the growing body of evidence that the structure of the whole complex must be taken into account when considering design and function. Furthermore, the potential to use lanthanides themselves to tune the properties of an antenna chromophore opens up a range of new prospects for sensing and control of luminescence properties. In this case, we are exploring the use of this system as both a sensitiser and a controllable luminescent tag.

\section{Notes and references}

\$ Obtained by estimating the 0,0 transition in a diethyl ether-ethanolisopropyl alcohol glass at $77 \mathrm{~K}$. See ESI $\dagger$ for further details.

1 (a) S. Faulkner, L. S. Natrajan, W. S. Perry and D. Sykes, Dalton Trans., 2009, 3890-3899; (b) J.-C. G. Bünzli, Chem. Rev., 2010, 110, 2729-2755; (c) C. P. Montgomery, B. S. Murray, E. J. New, R. Pal and D. Parker, Acc. Chem. Res., 2009, 42, 925-937; (d) J.-C. G. Bünzli and C. Piguet, Chem. Soc. Rev., 2005, 34, 1048-1077.
2 (a) L.-O. Pålsson, R. Pal, B. S. Murray, D. Parker and A. Beeby, Dalton Trans., 2007, 5726-5734; (b) G. Piszczek, B. P. Maliwal, I. Gryczynski, J. Dattelbaum and J. R. Lakowicz, J. Fluoresc., 2001, 11, 101-107; (c) S. V. Eliseeva, G. Auböck, F. van Mourik, A. Cannizzo, B. Song, E. Deiters, A.-S. Chauvin, M. Chergui and J.-C. G. Bünzli, J. Phys. Chem. B, 2010, 114, 2932-2937; (d) A. Picot, A. D'Aléo, P. L. Baldeck, A. Grichine, A. Duperray, C. Andraud and O. Maury, J. Am. Chem. Soc., 2008, 130, 1532-1533.

3 (a) J.-C. G. Bünzli and S. V. Eliseeva, J. Rare Earths, 2010, 28, 824-842; (b) N. Shavaleev, S. Pope, Z. R. Bell and S. Faulkner, Dalton Trans., 2003, 808-814; (c) A. M. Nonat, C. Allain, S. Faulkner and T. Gunnlaugsson, Inorg. Chem., 2010, 49, 8449-8456.

4 (a) A. Dadabhoy, S. Faulkner and P. G. Sammes, J. Chem. Soc., Perkin Trans. 2, 2000, 2359-2360; (b) A. Dadabhoy, S. Faulkner and P. G. Sammes, J. Chem. Soc., Perkin Trans. 2, 2002, 348-357; (c) J. D. Routledge, M. W. Jones, S. Faulkner and M. Tropiano, Inorg. Chem., 2015, 54, 3337-3345.

5 A. Beeby, S. Faulkner and J. A. G. Williams, J. Chem. Soc., Dalton Trans., 2002, 1918-1922.

6 D. Parker and J. A. G. Williams, Chem. Commun., 1998, 245-246.

7 M. P. Lowe, D. Parker, O. Reany, S. Aime, M. Botta, G. Castellano, E. Gianolio and R. Pagliarin, J. Am. Chem. Soc., 2001, 123, 7601-7609.

8 B. P. Burton-Pye and S. Faulkner, Chem. Commun., 2005, 259-261.

9 M. P. Placidi, A. J. L. Villaraza, L. S. Natrajan, D. Sykes, A. M. Kenwright and S. Faulkner, J. Am. Chem. Soc., 2009, 131, 9916-9917.

10 A. Dadabhoy, S. Faulkner and P. G. Sammes, J. Chem. Soc., Perkin Trans. 2, 2002, 348-357.

11 J. de Mendoza, P. M. Nieto, P. Prados and C. Sánchez, Tetrahedron, 1990, 46, 671-682.

12 J. Anderson, T. Byrne, K. J. Woelfel, J. E. Meany, G. T. Spyridis and Y. Pocker, J. Chem. Educ., 1994, 71, 715-718.

13 S. J. A. Pope, A. M. Kenwright, S. L. Heath and S. Faulkner, Chem. Commun., 2003, 1550-1551.

14 M. Woods, G. E. Kiefer, S. Bott, A. Castillo-Muzquiz, C. Eshelbrenner, L. Michaudet, K. McMillan, S. D. K. Mudigunda, D. Ogrin, G. Tircsó, S. Zhang, P. Zhao and A. D. Sherry, J. Am. Chem. Soc., 2004, 126, 9248-9256. 